\title{
Two-Year Results of Photodynamic Therapy Combined with Intravitreal Anti-Vascular Endothelial Growth Factor for Polypoidal Choroidal Vasculopathy; A Real Life Experience
}

\author{
Sibel Ahmet, Okkes Baz, Gokhan Demir, Ali Demircan, Zeynep Alkin, Abdullah Ozkaya, Alperen Koc, \\ Muhittin Taskapili
}

University of Healty Sciences, Beyoglu Eye Training and Research Hospital, Istanbul, Turkey

\begin{abstract}
Objectives: The aim of this study was to evaluate the 2-year outcomes of intravitreal ranibizumab (IVR) therapy in combination with photodynamic therapy (PDT) in patients with polypoidal choroidal vasculopathy (PCV).

Methods: Patients with PCV who presented at the clinic between January 2013 and January 2014 were reviewed retrospectively. Twenty-three eyes of 23 patients were included in this study. Indocyanine green angiography was performed to confirm the diagnosis of PCV in all patients. IVR was administered within a week following PDT, then followed by additional IVR as needed. Best corrected visual acuity (BCVA) measurement, biomicroscopic examination, and central macular thickness (CMT) measurement via optical coherence tomography at baseline and at 3, 6, 12, 18, and 24 months were performed. The mean change in BCVA and CMT at follow-up was compared with the baseline.

Results: A total of 23 eyes of 23 patients were included in this study. The mean age of the patients was $65.8 \pm 7.4$ years (range: 55-82 years). The mean BCVA (logMAR, or logarithm of the minimum angle of resolution) was $0.68 \pm 0.45$ at baseline, $0.67 \pm 0.45$ at 3 months $(p=0.24), 0.66 \pm 0.45$ at 6 months $(p=0.43), 0.69 \pm 0.43$ at 12 months $(p=0.95), 0.69 \pm 0.42$ at 18 months $(p=0.54)$, and $0.70 \pm 0.42$ at 24 months $(p=0.56)$. The mean CMT was $334.5 \pm 99.4 \mu \mathrm{m}$ at baseline, $313.4 \pm 96.1 \mu \mathrm{m}$ at 3 months $(p=0.27), 319.1 \pm 106.5 \mu \mathrm{m}$ at 6 months $(p=0.44), 303.52 \pm 128.33 \mu \mathrm{m}(p=0.17)$ at 12 months, $246.6 \pm 80.8 \mu \mathrm{m}$ at 18 months $(p=0.000 \mathrm{I})$, and $226.9 \pm 7 \mathrm{I} .7 \mu \mathrm{m}$ at 24 months $(p=0.000 \mathrm{I})$.

Conclusion: Verteporfin PDT administered in combination with IVR was an effective treatment for preserving VA in PCV for a 2-year period. Our results need to be confirmed in further studies in a real-life setting.

Keywords: Combined therapy, polypoidal choroidal vasculopathy, ranibizumab.
\end{abstract}

\section{Introduction}

Polypoidal choroidal vasculopathy (PCV) is characterized by a complex of branching vascular networks terminating in aneurysmal or polypoidal lesions (I, 2). Indocyanine green angiography (ICGA) is the optimal method to detect PCV, which is similar to an occult choroidal neovascular membrane in fundus fluorescein angiography, in the demonstration of vascular network structures and polyps $(3,4)$.

Recently, many studies have had successful results in the treatment of subfoveal PCV using photodynamic therapy (PDT), anti-vascular endothelial growth factor (anti-VEGF) agents, or a combination therapy with PDT and anti-VEGF agents (5). Though PDT is effective in illustrating branched 
network vaso-occlusion and polyps, it can be harmful to the physiological choriocapillary layer beyond the irradiated area, and repeated sessions of PDT result in persistent choriocapillary nonperfusion. The rationale for anti-VEGF treatment in PCV is based on the demonstration of VEGF expression in the aqueous humor of patients with PCV. Intravitreally injected anti-VEGF agents reduce the exudation and leakage from the vascular network and polyps. However, it has been demonstrated that the effect of anti-VEGF treatment alone on the regression of polyps was limited. Hence, combination therapy can exert synergistic effects on regressing polyps and better maintain visual acuity (VA) and retinal morphology when compared with PDT or anti-VEGF monotherapy (6).

The aim of this study was to evaluate the 2-year outcomes of intravitreal ranibizumab (IVR) therapy in combination with PDT in patients with PCV.

\section{Methods}

Patients with PCV who presented at the clinic between January 2013 and January 2014 were reviewed retrospectively. ICGA was performed to confirm the diagnosis in each patient. Symptomatic patients with subretinal reddish-orange spheroidal lesions on funduscopic examination, leakage on optical coherence tomography (OCT), and characteristic aneurysmal polypoidal lesions with a branching network of choroidal vessels seen on ICGA were included in the study. Patients were excluded if they had any of the following: previous treatment for PCV or intraocular surgery within the previous 30 days, verteporfin or fluorescein contraindication, pathological myopia, vascular diseases of the retina, diseases of the retinal pigment epithelium, or choroid disease other than PCV.

Patient consent was obtained to perform PDT and anti-VEGF therapy after informing them about their current condition, the natural course, and treatment success rate and risks, in accordance with the principles of the Declaration of Helsinki. IVR was administered within I week after PDT, and followed by additional IVR as needed.

For PDT, $6 \mathrm{mg} / \mathrm{m}^{2}$ verteporfin (Visudyne; Novartis AG, Basel, Switzerland) was administered intravenously at a rate of $3 \mathrm{~mL} /$ minute in the form of $30 \mathrm{~mL}$ of solution in $5 \%$ dextrose. The laser was applied at a wavelength of $689 \mathrm{~nm}$ with a power of $600 \mathrm{~mW} / \mathrm{cm}^{2}$ for 83 seconds, 15 minutes after the initiation of the infusion. The largest linear diameter of polyps and abnormal, dilated choroidal vascular networks was measured using ICGA. The spot size of the laser beam was calculated by adding $1000 \mu$ to the largest linear diameter of the lesion to be treated.

All injections were administered under sterile conditions and under topical anesthesia. Sterilization of the eye lids and eyelashes was achieved with $10 \%$ povidone iodine; steriliza- tion of the conjunctival sac was achieved with $5 \%$ povidone iodine.

Ranibizumab $(0.5 \mathrm{mg} / 0.05 \mathrm{~mL})$ was injected intravitreally with a $27-\mathrm{G}$ needle from 3 to $4 \mathrm{~mm}$ distance to the limbus. The use of $0.5 \%$ moxifloxacin was recommended 5 times daily for I week after the injection.

Intravitreal administration of ranibizumab was considered when intraretinal/subretinal fluid observed on OCT was related to polypoidal lesions or a patient had decreased VA.

Thereafter, patients were followed in accordance with the retreatment criteria for IVR according to the parameters recommended in the PRONTO study: evidence of persistent fluid on OCT at least I month after the previous injection, an increase in OCT central macular thickness (CMT) $\geq 100 \mu \mathrm{m}$, a new macular hemorrhage, or a decrease in best corrected visual acuity (BCVA) $>5$ letters (7). Retreatment with PDT was performed when ICGA showed active polypoidal lesions persisted 3 months after the previous PDT treatment.

Initially, a full ophthalmic examination, including measurement of BCVA with a Snellen chart, anterior and posterior segment examination with slit-lamp biomicroscopy, color fundus photography, fluorescein angiography (HRA-2; Heidelberg Engineering, Heidelberg, Germany), and OCT imaging (Spectralis; Heidelberg Engineering, Heidelberg, Germany) were performed. The demographic details of the patients, the duration of the follow-up period, the number of IVR injections and PDT sessions, and BCVA and CMT at baseline and at 3, 6, 12, 18, and 24 months were recorded. A paired-sample t-test was used for statistical analysis. Significance was assessed at $p<0.05$.

\section{Results}

Twenty-three eyes of 23 patients (II right, 12 left) were included in this study. The mean age of the patients was $65.8 \pm 7.4$ years (range: $55-82$ years). Table I is a summary of the demographic data of the patients.

The mean BCVA (logMAR, or logarithm of the minimum

Table I. Baseline characteristics of patients with PCV

Age (years)

Mean \pm SD

$65.8 \pm 7.4$

Range

$55-82$

Gender

Male (\%)

Female (\%)

BCVA at baseline (logMAR)

$0.68 \pm 0.45$

CMT at baseline $(\mu)$

$334.5 \pm 99.4$

BCVA: best corrected visual acuity; CMT: central macular thickness; PCV: polypoidal choroidal vasculopathy. 


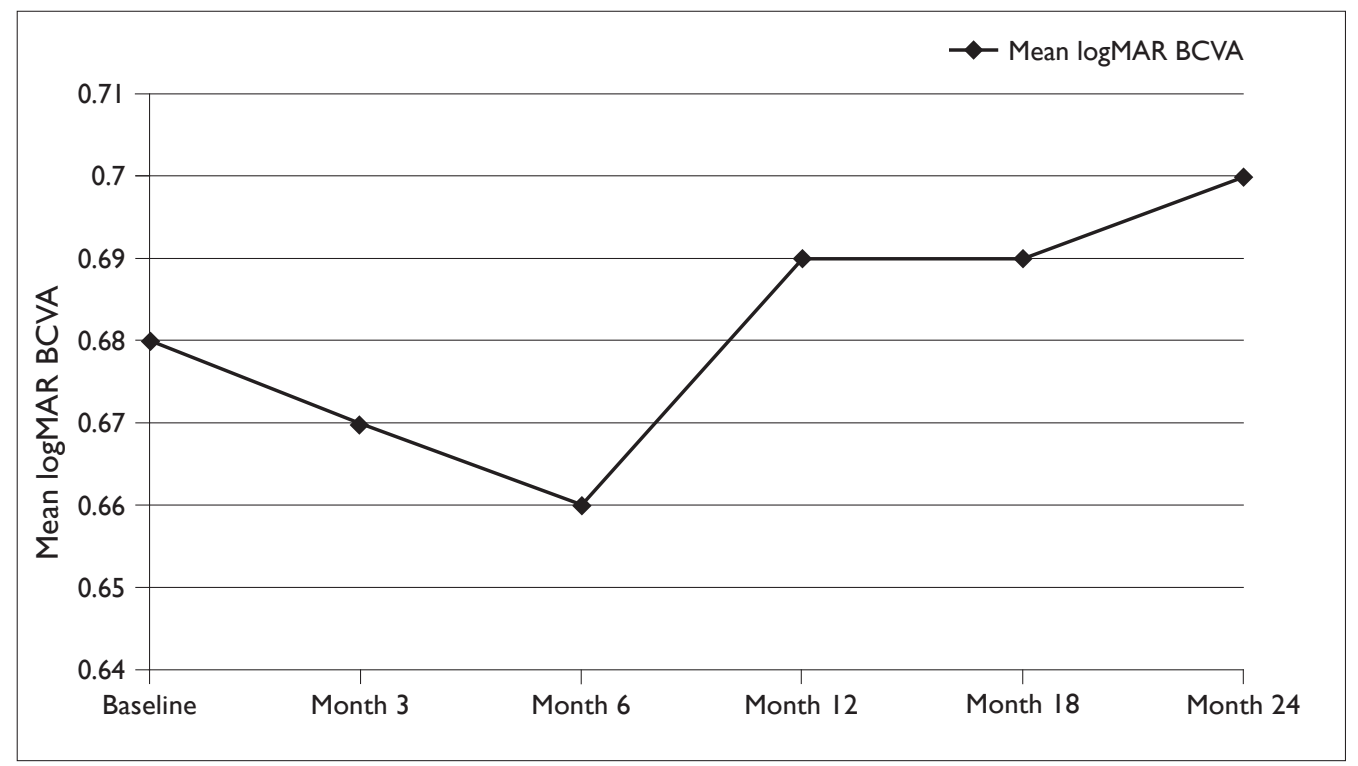

Figure I. The change in mean logMAR best corrected visual acuity over time.

BCVA: best corrected visual acuity.

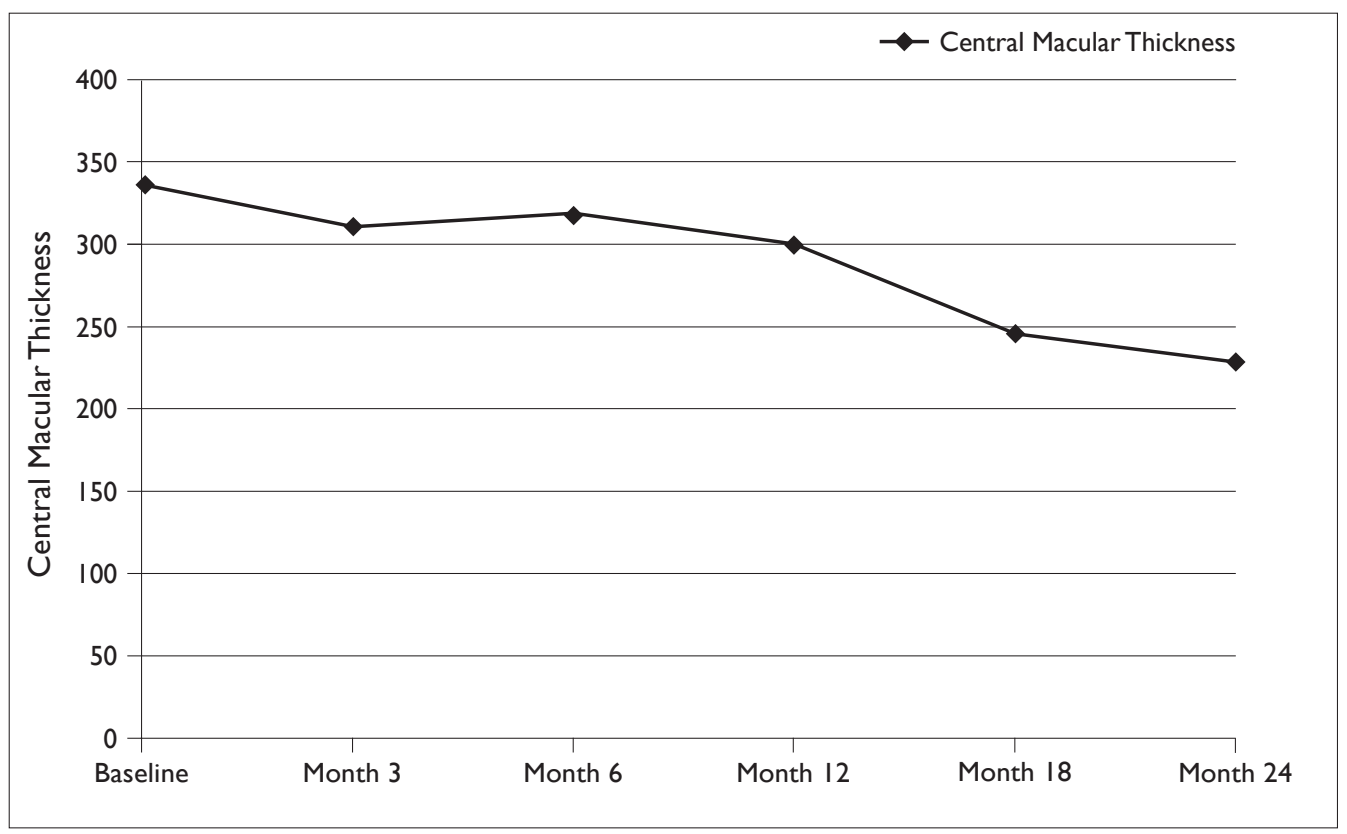

Figure 2. The change in mean central macular thickness observed with optical coherence tomography over time.

angle of resolution) was $0.68 \pm 0.45$ at baseline, $0.67 \pm 0.45$ at 3 months $(p=0.24), 0.66 \pm 0.45$ at 6 months $(p=0.43)$, $0.69 \pm 0.43$ at 12 months $(p=0.95), 0.69 \pm 0.42$ at 18 months $(p=0.54)$, and $0.70 \pm 0.42$ at 24 months $(p=0.56)$. Compared with the baseline measurements, no statistically significant difference was found during follow-up. Figure I illustrates the changes in mean logMAR BCVA.

The mean CMT was $334.5 \pm 99.4 \mu \mathrm{m}$ at baseline, $3 \mid 3.4 \pm 96.1 \mu \mathrm{m}$ at 3 months ( $p=0.27), 319.1 \pm 106.5 \mu \mathrm{m}$ at 6 months $(p=0.44), 303.52 \pm 128.33 \mu \mathrm{m}(p=0.17)$ at 12 months,
$246.6 \pm 80.8 \mu \mathrm{m}$ at I 8 months $(\mathrm{p}=0.000 \mathrm{I})$, and $226.9 \pm 7 \mathrm{I} .7 \mu \mathrm{m}$ at 24 months $(p=0.0001)$. Compared with the baseline, no statistically significant difference was found at 3, 6, and 12 months. However, a statistically significant decrease was observed at 18 and 24 months. The changes in mean CMT are provided in Figure 2.

The pretreatment and posttreatment ICGA and OCT findings can be seen in Figure 3.

During the 24-month follow-up period, the mean number of PDT sessions was I. $5 \pm 0.5$ (range: $\mathrm{I}-3$ ) and the mean 

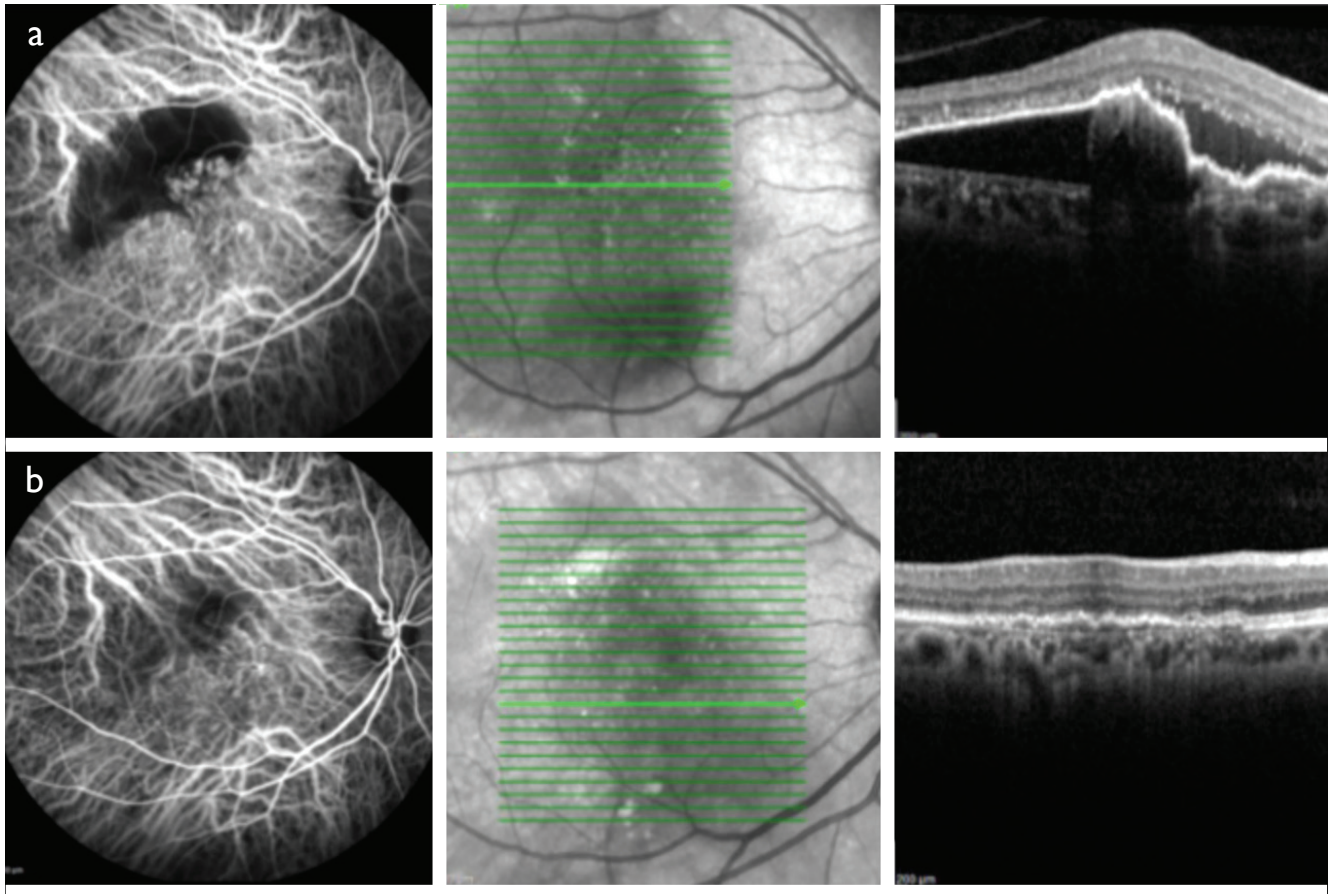

Figure 3. (a) ICGA and OCT findings before PDT combined with anti-VEGF. (b) ICGA and OCT findings after PDT combined with anti-VEGF.

Anti-VEGF: anti-vascular endothelial growth factor; ICGA: indocyanine green angiography; OCT: optical coherence tomography; PDT: photodynamic therapy.

number of IVR applications was $5.3 \pm 1.06$ (range: $3-7$ ). At the end of 24 months, 14 patients $(60.9 \%)$ were referred to follow-up without any treatment, 8 patients (34.8\%) were scheduled for reinjection of IVR, and re-PDT was recommended for I patient (4.3\%). A subretinal hemorrhage occurred in 4 patients ( $17.2 \%)$.

\section{Discussion}

Little is known about the pathogenesis of PCV. It remains unclear whether PCV represents abnormal vessels from the choroidal circulation or is a variant of choroidal neovascularisation (I). It is well known, however, that PCV primarily involves the inner choroidal vasculature that is well differentiated from the middle and larger choroid vessels. PDT and anti-VEGF agents are the current treatment modalities for PCV. PDT induces regression or resolution of polyps via its angio-occlusive mechanism of action. PDT appears to be safe and effective in patients with active and symptomatic subfoveal PCV lesions. Increased VEGF levels have been observed in PCV patients (23) Therefore, anti-VEGF therapy might theoretically be beneficial in PCV treatment. Recent studies have reported that intravitreal anti-VEGF injections help to stabilize VA and reduce serous retinal detachment in the short term. However, intravitreal injections of anti-VEGF as a monotherapy have limitations in preventing the aggravation of polypoidal lesions (I I); thus, a combination of anti-VEGF injection and PDT has been attempted as an alternative treatment.

PDT is an established treatment modality for PCV (8). The mechanism of action involves a vaso-occlusive effect. When PDT activates the photosensitizer verteporfin at the site of the laser application, it induces vascular thrombosis, reduced perfusion, and PCV regression $(9,10)$. A high polyp regression rate of $82 \%$ to $95 \%$ with PDT monotherapy has been reported $(9,14,15)$.

It has been demonstrated in many studies that PDT alone had a success rate of $80 \%$ to $95 \%$ in the treatment of subfoveal PCV (II). Gomi et al. (I2) reported that BCVA in $84 \%$ of patients remained stable or increased after PDT, and $85 \%$ of polyps had regressed at I year. In a study that was presented as the result of I year of follow-up in patients who had undergone PDT, Senturk et al. (13) found that $60 \%$ of the cases had increased VA and $40 \%$ had stabilized. Otani et al. (14) demonstrated in a prospective study of 45 eyes treated with PDT that $82.2 \%$ of the polypoidal lesions had regressed at the end of I year. Furthermore, Muslubas et al. (16) showed that BCVA in $89 \%$ of PDT patients remained stable or increased, and $67 \%$ of polyps had regressed at 24 months.

Several studies have determined that intravitreal anti-VEGF combined with PDT in PCV patients is more effective than single anti-VEGF therapy in increasing VA, and 
preventing subretinal hemorrhage and polyp recurrence (20, $2 \mathrm{I}, 22)$. A combined PDT and intravitreal anti-VEGF injection was reported to increase BCVA and to decrease foveal thickness in a I2-month follow-up (17).

Ruamviboonsuk et al. (14) reported that $58.3 \%$ of patients had a BCVA gain of 15 letters or more, and the polyps in all patients regressed without recurrence with combined therapy. In the study performed by Muslubas et al., $88 \%$ of the patients who underwent combined treatment had a significant improvement in BCVA. However, a statistically significant decrease in CMT was observed (16). The EVEREST trial was the first randomized, controlled trial investigating whether PDT, either as a monotherapy or in combination with IVR, was more efficacious than ranibizumab monotherapy in achieving complete polyp regression as assessed by ICGA. In this study, there was no difference between PDT alone and combined anti-VEGF treatment in terms of BCVA gain. The rate of complete regression in polyps was found to be $77.8 \%$ with combined treatment, $71.4 \%$ with PDT monotherapy, and $28.6 \%$ with ranibizumab monotherapy $(6,19)$

A mean of 5 injections were performed in the present study. In a study conducted by Marcus et al. (24), a mean of 7.2 injections per eye was administered over a 24-month follow-up period. They observed a I.2 Snellen letter-increase at month 24 compared with the baseline. In contrast, we observed no change in BCVA compared to the initial measurement at 24 months. It can be speculated that this was probably due to the smaller number of injections.

The current study has some limitations. First, this was a retrospective study. Additionally, this study had a small sample size and was without a control group.

In conclusion, our findings suggested that combined PDT and IVR was effective in preserving VA and retinal morphology in the long-term. To establish the sustained beneficial effects of combination therapy, further investigation with controlled studies is needed.

\section{Disclosures}

Financial Disclosure: This retrospective study was not supported by any company. None of the authors has financial or proprietary interests in any material or method mentioned. These data have not been previously published.

Peer-review: Externally peer-reviewed.

Conflict of Interest: None declared.

Authorship Contributions: Involved in design and conduct of the study (ZA, AO, SA, OB); preparation and review of the study (ZA, AO, AD, GD, MT); data collection (ZA, AO, SA, OB, GD); and statistical analysis (ZA, AK, AD, GD).

\section{References}

I. Yannuzzi LA, Sorenson J, Spaide RF, Lipson B. Idiopathic polypoidal choroidal vasculopathy (IPCV). Retina 1990;10:1-8.
2. Spaide RF, Yannuzzi LA, Slakter JS, Sorenson J, Orlach DA. Indocyanine green videoangiography of idiopathic polypoidal choroidal vasculopathy. Retina 1995; 15:100-10. [CrossRef]

3. Lim LS, Mitchell P, Seddon JM, Holz FG, Wong TY. Age-related macular degeneration. Lancet 20I2;379:I728-38. [CrossRef]

4. Stangos AN, Gandhi JS, Nair-Sahni J, Heimann H, Pournaras C], Harding SP. Polypoidal choroidal vasculopathy masquerading as neovascular age-related macular degeneration refractory to ranibizumab. Am J Ophthalmol 2010;150:666-73. [CrossRef]

5. Wong RL, Lai TY. Polypoidal choroidal vasculopathy: an update on therapeutic approaches. J Ophthalmic Vis Res 2013;8:359-7I.

6. Çıtırık M, Teke MY. Polipoid koroidal vaskülopati. Available at: http://www.ulucanlarretina.com. Accessed Jan I, 2016.

7. Lalwani GA, Rosenfeld PJ, Fung AE, Dubovy SR, Michels S, Feuer $W$, et al. A variable-dosing regimen with intravitreal ranibizumab for neovascular age-related macular degeneration: year 2 of the PrONTO Study. Am J Ophthalmol 2009; |48:43-58.el.

8. Imamura Y, Engelbert M, lida T, Freund KB, Yannuzzi LA. Polypoidal choroidal vasculopathy: a review. Surv Ophthalmol 2010;55:50I-15. [CrossRef]

9. Akaza E, Yuzawa M, Matsumoto Y, Kashiwakura S, Fujita K, Mori R. Role of photodynamic therapy in polypoidal choroidal vasculopathy. Jpn J Ophthalmol 2007;5 I:270-7. [CrossRef]

10. Lee WK, Lee PY, Lee SK. Photodynamic therapy for polypoidal choroidal vasculopathy: vaso-occlusive effect on the branching vascular network and origin of recurrence. Jpn J Ophthalmol 2008;52:108-15. [CrossRef]

I I. Gomi F, Sawa M, Sakaguchi H, Tsujikawa M, Oshima Y, Kamei $M$, et al. Efficacy of intravitreal bevacizumab for polypoidal choroidal vasculopathy. Br J Ophthalmol 2008;92:70-3. [CrossRef]

12. Gomi F, Ohji M, Sayanagi K, Sawa M, Sakaguchi H, Oshima Y, et al. One-year outcomes of photodynamic therapy in age-related macular degeneration and polypoidal choroidal vasculopathy in Japanese patients. Ophthalmology 2008; I 15:|4|-6. [CrossRef]

13. Şentürk F, Karaçorlu SA, Özdemir H, Karaçorlu M. Polipoidal koroidal vaskülopati olgularında fotodinamik tedavi. Turk J Ophthalmol 2009;39:44I-5.

14. Otani A, Sasahara M, Yodoi Y, Aikawa H, Tamura H, Tsujikawa $A$, et al. Indocyanine green angiography: guided photodynamic therapy for polypoidal choroidal vasculopathy. Am J Ophthalmol 2007; |44:7-|4. [CrossRef]

15. Chan WM, Lam DS, Lai TY, Liu DT, Li KK, Yao Y, et al. Photodynamic therapy with verteporfin for symptomatic polypoidal choroidal vasculopathy: one-year results of a prospective case series. Ophthalmology 2004; I I I: I 576-84. [CrossRef]

16. Sayman Muslubaş I, Hocaoğlu M, Arf S, Özdemir H, Karaçorlu M. Treatment Outcomes in Patients with Polypoidal Choroidal Vasculopathy. Turk J Ophthalmol 2016;46:16-20. [CrossRef]

17. Lee YH, Lee EK, Shin KS, Lee KM, Kim JY. Intravitreal ranibizumab combined with verteporfin photodynamic therapy for treating polypoidal choroidal vasculopathy. Retina 201 I;3 I:I287-93. 
18. Ruamviboonsuk P, Tadarati M, Vanichvaranont S, Hanutsaha P, Pokawattana N. Photodynamic therapy combined with ranibizumab for polypoidal choroidal vasculopathy: results of a I-year preliminary study. Br J Ophthalmol 20 I0;94:I045-5I. [CrossRef]

19. Koh A, Lee WK, Chen LJ, Chen SJ, Hashad Y, Kim H, et al. EVEREST study: efficacy and safety of verteporfin photodynamic therapy in combination with ranibizumab or alone versus ranibizumab monotherapy in patients with symptomatic macular polypoidal choroidal vasculopathy. Retina 2012;32:1453-64.

20. Lai TY, Chan WM, Liu DT, Luk FO, Lam DS. Intravitreal bevacizumab (Avastin) with or without photodynamic therapy for the treatment of polypoidal choroidal vasculopathy. $\mathrm{Br} \mathrm{J}$ Ophthalmol 2008;92:66I-6. [CrossRef]

2I. Koh AH; Expert PCV Panel, Chen LJ, Chen SJ, Chen Y, Giridhar
A, et al. Polypoidal choroidal vasculopathy: evidence-based guidelines for clinical diagnosis and treatment. Retina 2013;33:686-7|6. [CrossRef]

22. Song MH, Ryu HW, Roh YJ. One-year results of intravitreal ranibizumab with or without photodynamic therapy for polypoidal choroidal vasculopathy. Ophthalmologica 201 I;226: I 19-26.

23. Matsuoka M, Ogata N, Otsuji T, Nishimura T, Takahashi K, Matsumura M. Expression of pigment epithelium derived factor and vascular endothelial growth factor in choroidal neovascular membranes and polypoidal choroidal vasculopathy. $\mathrm{Br} \mathrm{J}$ Ophthalmol 2004;88:809-15. [CrossRef]

24. Marcus DM, Singh H, Lott MN, Singh J, Marcus MD. Intravitreal ranibizumab for polypoidal choroidal vasculopathy in non-Asian patients. Retina 2013;33:35-47. [CrossRef] 